\title{
Fuel Shape Effect on the Deterministic Properties of Turbulent Diffusion Flames
}

\author{
YUJI HASEMI \\ Building Research Institute \\ Ministry of Construction \\ Tatehara 1, Tsukuba-City \\ Ibaraki-ken 305, Japan
}

\section{MITSURU NISHIHATA}

Center for Fire Science and Technology

Science University of Tokyo

Noda-City, Chiba-ken 278, Japan

\section{ABSTRACT}

Measurements of flame height and temperature distribution above fuel surface were made on rectangular propane burners in a huge calm englosyrg. Flame height is represented as a function of $Q_{\text {mod }}=Q / \rho_{O} \mathrm{CpT}_{\mathrm{o}} \mathrm{g}^{1 / 2} \mathrm{AB}^{3 / 2}$, where $A$ and $B$ are the length of the shorter and longer side of a fuel respectively. Vertical distribution of temperature above the center of a fuel is compared with temperature profiles for square fuels and for line fuels. Finally a practical criterion for the approximation of rectangular fuels by square and line source is proposed.

key words: turbulent flame, flame height, temperature, aspect ratio.

\section{INTRODUCTION}

Deterministic properties of turbulent diffusion flames such as flame height and temperature above the flame have been studied for various purposes in the field of fire research e.g.,[1-8]. Dimensional analysis of the flame gegmetry has established the dependence of the ratio of flame height on $\mathrm{Q} / \mathrm{D}^{5 / 2}[1]$, and its significance ${ }_{1} s$ ften represented by a dimensionless heat release rate, $Q^{*}=\rho_{0} \mathrm{CpT} g / \mathrm{D}^{5 / 2}[5]$ or some parameter representing an essentially same implication [6]. However, while there are plenty of fuel shapes in actual fires, most of current studies have assumed relatively ideal fuel geometry, e.g. point source, round or square surface, probably for the simplicity of analysis.

For rectangular "nonideal" fuels, we can expect some qualitative relation between the deterministic properties and aspect ratio from the established knowledge on the mechanist of ideal fuels; as a result of the increase of entraimment by the increase of aspect ratio an increase of aspect ratio for a given heat release rate is expected to result in the decrease of flame height. Decrease of flame height will further result in the decrease of temperature and velocity along the axis of the turbulent plume above the flame since these properties are strongly dependent on the flame height. Such influence of the fuel shape on the flame behavior is also expected to vanish for a flame considerably higher than the fuel size. The purpose of this study is to quantify these effects by experiments for the ease of the prediction of deterministic properties of turbulent diffusion flames in actual fires. 
The dimensionless parameter corresponding to $Q^{*}$ for a rectangular fuel surface is

$\mathrm{Q}_{\bmod }^{*}=\mathrm{Q} / \rho_{\mathrm{O}} \mathrm{C}_{\mathrm{p}} \mathrm{T}_{\mathrm{O}} \mathrm{g}^{1 / 2} \mathrm{~A}{ }^{3 / 2} \mathrm{~B}$

where $A$ and $B$ are lengths of the shorter and longer side respectively. This modified dimensionless heat release rate is identical to $Q$ for a square fuel, and for $B \rightarrow \infty$ limit, it becomes identical to

$\mathrm{Q}_{l}^{*}=\mathrm{Q}_{l} / \rho_{\mathrm{O}} \mathrm{C}_{\mathrm{p}} \mathrm{T}_{\mathrm{o}} \mathrm{g}^{1 / 2} \mathrm{~A}^{3 / 2}$

where $Q_{l}$ is heat release rate per unit length from a line fire. For square fuels, $Q$ dependence of flame height is described as

$\mathrm{L}_{\mathrm{F}}=\gamma \mathrm{Q}^{* \mathrm{n}_{\mathrm{D}}}$

where $n=2 / 5$ for $Q^{*} \geq 1$, and $n$ becomes larger for $Q^{*}<1[7]$; this implies that the influence of fuel size will vanish for $Q * 1$, or for relatively tall flames. From this result, the power representing the $Q_{*}^{*}$ dependence of $\mathrm{L}_{\mathrm{F}} / \mathrm{A}$ for line fires is expected to yield $2 / 3$ for large $Q$ values; this relation has been eventually obtained for $Q \gtrsim 1$ of line fires against a vertical wa11[9].

From these correlations, it is expected for "nonideal" fires that , for flames considerably higher than the longer side of a fuel, flame height becomes independent of fuel geometry and proportional to $2 / 5$ power of heat release rate, while for low heat release rates, the hejght of flame from a rectangular fuel becomes closer to that from line fires. Assuming $Q^{*}$ mo* dependence of $L_{F}$ and proportionality of $L_{F}$ to $2 / 5$ power of $Q$ for large $Q$ w values, flame height for a fuel of aspect ratio, $\alpha$, is expected to folpow

$\mathrm{L}_{\mathrm{F}}=\gamma \alpha^{2 / 5} \mathrm{Q}_{\bmod }^{*}{ }^{2 / 5} \mathrm{~A}$

if excess air ratio for flames above rectangular fuels is consistent with that for square fuels.

For vertical distribution of excess temperature above the center of a fuel surface, similarity analysis on potht source and line source plumes has led to the dependence of $\theta$ on $z /\left(Q^{* 2 / 5} \mathrm{D}\right)$ for square fuels $[7,11]$ and $\theta$ on $\mathrm{z} /\left(\mathrm{Q}_{l}{ }^{*} \mathrm{~A}\right)$ for line fires $[10]$. It is naturally assumed that for fuels of relatively small aspect ratio $\theta$ would follow the relation obtained for square fuels, while for fuels of large aspect ratio $\theta$ would follow the relation for line fires. From the analogy of the flame height analysis, $\theta$ for a fire of relatively smanll aspect ratio is expected to be represented as a function of $\mathrm{z} /\left(\alpha^{2 / 5} \mathrm{Q}^{\mathrm{r}}\right.$ ad $\left.\mathrm{A}\right)$. However, since a fuel shape effect is believed to be significant only in the near field of a flame, it is also expected that the square-fuel theory would still hold in the far field of flames from a slender fuel, while the line-fuel theory may hold in the near field above a fuel of small aspect ratio. These expected relations shall be examined by the following experiments.

\section{EXPERIMENTAL DESCRIPTION}

The experiments were conducted using a $0.1 \mathrm{~m} \times 1.0 \mathrm{~m}$ and a $0.2 \mathrm{~m} \times 1.0 \mathrm{~m}$ 


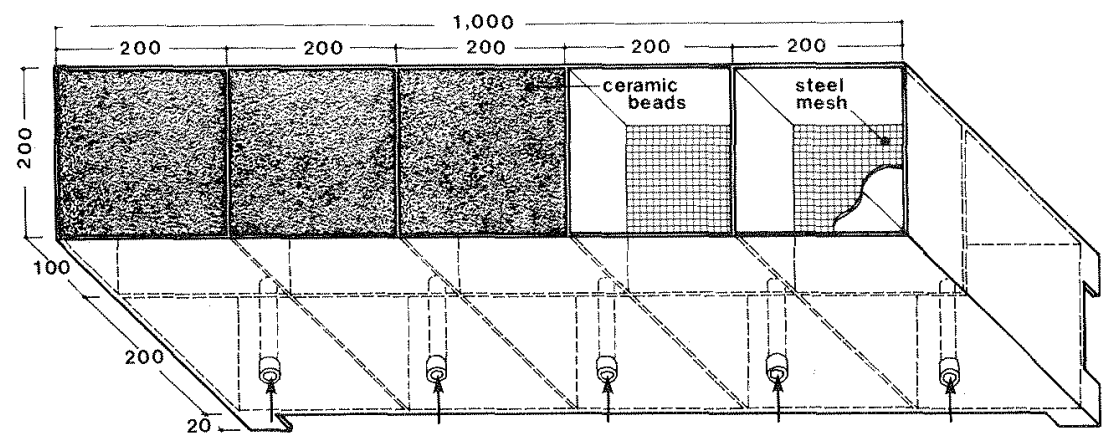

Figure 1 Structure of the $0.20 \mathrm{~m} \times 1.0 \mathrm{~m}$ burner

rectangular porous burners with propane as the fuel. The interior of the $0.2 \mathrm{~m} \times 1.0 \mathrm{~m}$ burner was divided into five $0.2 \mathrm{~m} \times 0.2 \mathrm{~m}$ square sub-burners such that aspect ratio could be changed from 1 to 5(Figure 1). Therefore, aspect ratio of the fuel was chosen to be $1,2,3,4,5$, and 10 . The burners were filled with ceramic beads of approximately $5 \mathrm{~mm}$ diameter, and the height of the exit of each burner was approximately $0.50 \mathrm{~m}$ above the floor of a laboratory, $27 \mathrm{~m}$ by $20 \mathrm{~m}$ in plan and $27 \mathrm{~m}$ high without artificial floor surround at the level of the burner exits. For each burner exit conditions, heat release rate was changed from approximately $20 \mathrm{~kW}$ to $300 \mathrm{~kW}$. This heat input range corresponds to the $Q$ range from approximately 0.3 to 5 . this condition covers $Q$, malues for the combustion of usual furnitures and 1 iquid fuels $[7,11,12]$.

Observations were made on the geometry of visible flames and the vertical temperature distribution above the center of the burner exits. Flame was monitored by a video camera during each experiment, and data of the flame height were obtained from observation of the videotape; the reported values of flame height are the average of the height of flame-tips observed for more than 3 minutes at the intervals of $1 \mathrm{~s}$. While there are many definitions of flame height, this definition was chosen for the simplicity in measurement and relatively good consistency among observers.

Temperature measurements were made using $0.20 \mathrm{~mm}$ diameter chromel-alumel thermocouples. The time constant of the temperature measurement system is approximately $10 \mathrm{~s}$. No corrections have been made for the radiation and conduction losses from the junction of each thermocouple. Soot buildup considerably thinner than the radius of the thermocouple junctions was observed on some thermocouples after each measurement. These errors may lead to an underestimate of gas temperature; for $0.20 \mathrm{~mm}$ diameter chromel-alumel thermocouples with an emissivity of around 0.9 , the error due to radiation loss will range from 2 to $20 \%$ over the temperature range $300-1,000^{\circ} \mathrm{C}$. To eliminate the influence of accidental sway of the flame, temperature was monitored at each height not only just above the burner center but also at two different points $5 \mathrm{~cm}$ apart from the center in the direction of shorter side. The reported values of temperature are the average of the maximum temperature at each height at the interval of $10 \mathrm{~s}$ over 3 minutes during which the temperature above the burner center was higher than the other two. 
Flame Height

Flame height data are correlated with heat release rate in two different ways; one directly between $\mathrm{L}_{\mathrm{F}}$ and $\mathrm{Q}$, and the other between $\mathrm{L}_{\mathrm{F}} / \mathrm{A}$ and $Q *$. From the former analysis, it is expected that for, large heat input, monfluence of the size and shape of fuel will become insignificant and all flame height data will fall on the $\mathrm{L}_{\mathrm{F}}-\mathrm{Q}$ relation obtained for square fuels. On the other hand, for relatively low heat release rate, influence of fuel shape will become dominant and flame height data on rectangular fuels will fall on the relation for line fuels in the graph for $\mathrm{L}_{\mathrm{F}} / \mathrm{A}-\mathrm{Q}{ }^{*} \bmod$.

Figure 2 shows the $\mathrm{L}_{\mathrm{F}}-\mathrm{Q}$ relationship. For the $0.20 \mathrm{~m}$ square burner, $\mathrm{L}_{\mathrm{F}}$ is proportional to $Q^{2 / 5}$ for $Q \geqslant 20 \mathrm{~kW}$, whereas flame height for the $0.10 \mathrm{~m} \mathrm{~F}$ $1.0 \mathrm{~m}$ burner is proportional to $Q^{2 / 3}$ for $Q \leqslant 100 \mathrm{~kW}$. While flame heights for all rectangular burners are shorter than that for the square burner, flame height for the $0.20 \mathrm{~m} \times 0.40 \mathrm{~m}$ burner is very close to that for the $0.20 \mathrm{~m}$ square burner for $Q \geqslant 80 \mathrm{~kW}$; it means the disappearance of shape effect in this regime of the $0.20 \mathrm{~m} \times 0.40 \mathrm{~m}$ burner. For aspect ratio greater than 2 , the fuel shape effect is found to be considerably significant for the examined experimental conditions. Flame height for the $0.20 \mathrm{~m} \times 1.0 \mathrm{~m}$ burner is generally very close to the data for the $0.10 \mathrm{~m} \times 1.0 \mathrm{~m}$ burner.

Figure 3 shows the $\mathrm{L}_{\mathrm{F}} / \mathrm{A}-\mathrm{Q}^{*}$, relationship; for the $0.10 \mathrm{x} 1.0 \mathrm{~m}$ burner, $\mathrm{L}_{\mathrm{F}} / \mathrm{A}$ is proportional to $2 / 3$ power of $\mathrm{Q}^{*} \bmod$ for $\mathrm{Q}$ mod $\lesssim 3$, and the ${ }_{\mathrm{F}} / \mathrm{A}-\mathrm{Q}$ * ${ }^{\mathrm{F}}$ relationships for aspect ratio $\geqslant 3$ are very close to this for approximately $Q$ " $<1$. Assuming the "line source bound" along these data, it is concluded that flame height from any "nonideal" fire will fal1 between the line-source bound and the square-source bound. Flame height for the $0.20 \mathrm{~m} \times 0.40 \mathrm{~m}$ burner for $Q^{\times}$approaches to approximately 2 a times $L_{F}$ for the $0.20 \mathrm{~m}$ square burner as expected from equation(4).

Temperature

In order to obtain reference vertical temperature distribution for line and square fuels, maximum excess temperature at each height is correlated against $z / Q^{*} / 2 \mathrm{~A}$ and $z / Q^{*}$ mod $\mathrm{A}$ for the $0.1 \mathrm{~m} \times 1.0 \mathrm{~m}$ burner and the $0.2 \mathrm{~m} \times 0.2 \mathrm{~m}$ burner respectively( $\mathrm{m}$ igures 4,5 ). The temperature data for the $0.1 \mathrm{~m} \times 1.0 \mathrm{~m}$ burner appear to cluster densely along one curve, and excess 59 mperature appears to be inversely proportiona1 to $\mathrm{z} / \mathrm{Q}{ }^{*}{ }^{2}{ }^{2} \mathrm{~A}$ for $\mathrm{z} / \mathrm{Q}$ ( $27 \mathrm{~A}_{\mathrm{A}} \geq 7.0$, as expected from the turbulent line plume theory[10]. However, the slope for the data in the far fleld of low $Q$, fires is slightly less steep than -1 ; this implies some virtual source moffect.

The temperature data for the $0.2 \mathrm{~m} \times 1.0 \mathrm{~m}, 0.2 \mathrm{~m} \times 0.8 \mathrm{~m}, 0.2 \mathrm{~m} \times 0.6 \mathrm{~m}$, and $0.2 \mathrm{~m} \times 0.4 \mathrm{~m}$ burnex correlated against $\mathrm{z} / \mathrm{Q}^{*}$ ad $\mathrm{A}$ are shown in Figures $6-9$; the results for $\alpha \geqslant 4$ are very close to the relation for the $0.1 \mathrm{~m} x$ $1.0 \mathrm{~m}$ burner, whereas for $\alpha \leqslant 3$ clustering of the data is seen only within the flame region. Moreover, for $\alpha \leqslant 3$, the power of height representing $\theta_{\text {, }}$ in the far field is evidently closer to $-5 / 3$ than to -1 . Maximum excess temperature at each height for the $0.2 \mathrm{~m} \times 2 \% 4 \mathrm{~m}$ and $0.2 \mathrm{~m} \times 0.6 \mathrm{~m}$ rectangular burner is also correlated against $\mathrm{z} / \mathrm{Q}$ mod $\mathrm{A}$ as shown in Figures 10,11 . For each of these burners, the temperature data beyond the height of flame tips appear to cluster along one curve, and the slope representing the power of height for excess temperature is approximately $-5 / 3$. The difference of the temperature among the burners arose from the 


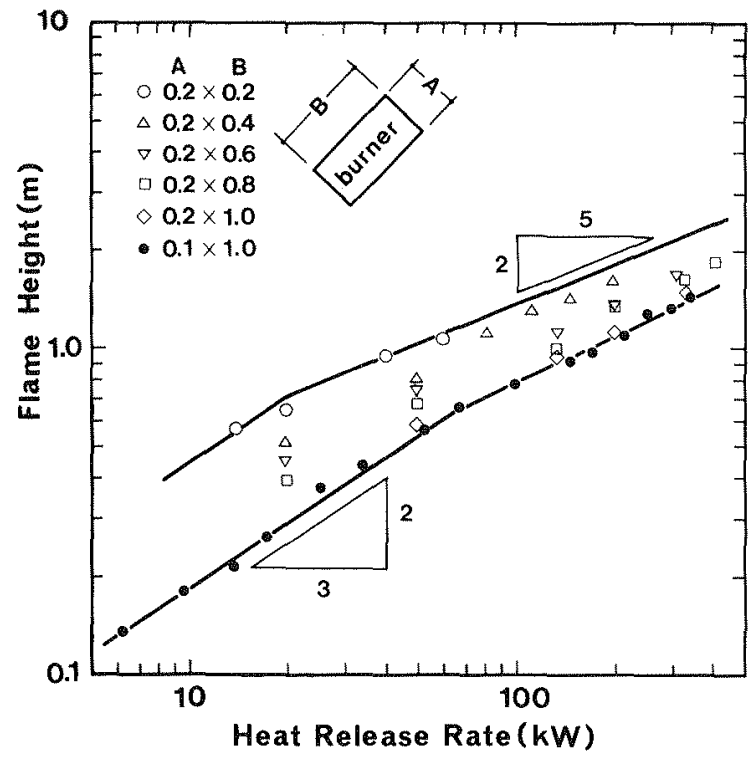

Figure 2 Flame height vs. Heat release rate

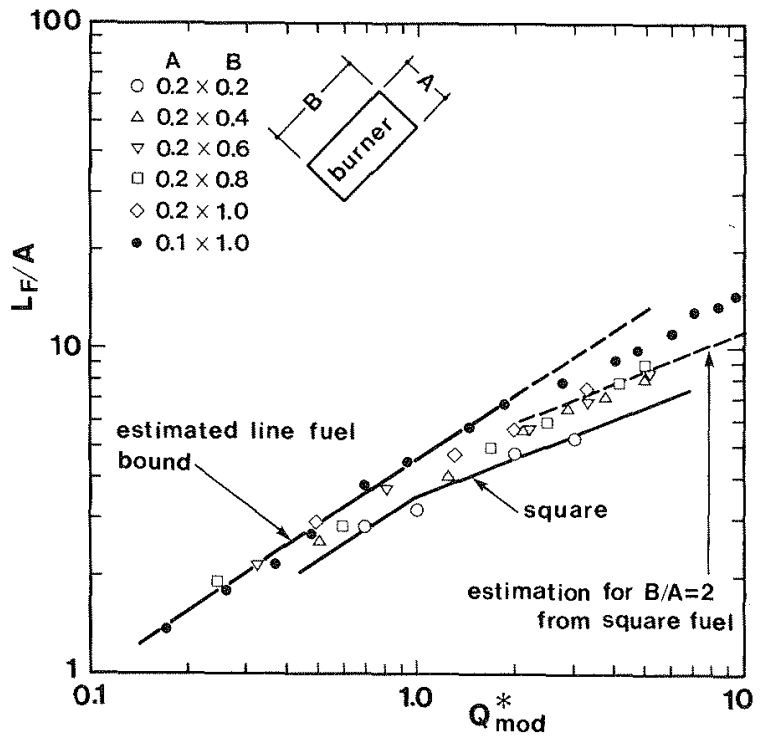

Figure $3 \mathrm{~L}_{\mathrm{F}} / \mathrm{A}$ vs. $\mathrm{Q}_{\bmod }{ }^{*}$ 
normalization of $\mathrm{z}$ by $\mathrm{Q}^{*}{ }_{\bmod }^{2 / 5} \mathrm{~A} ; 2$ py the analogy from the flame height analysis, bias of the curves by $\alpha^{2 / 3}$ is expected to lead to the agreement among the results. The curve shown in Figures 10 and 11 represents this operation. The temperature data in the far field for rectangular fuels of $\alpha=2,3$ seem to be close to this biased curve.

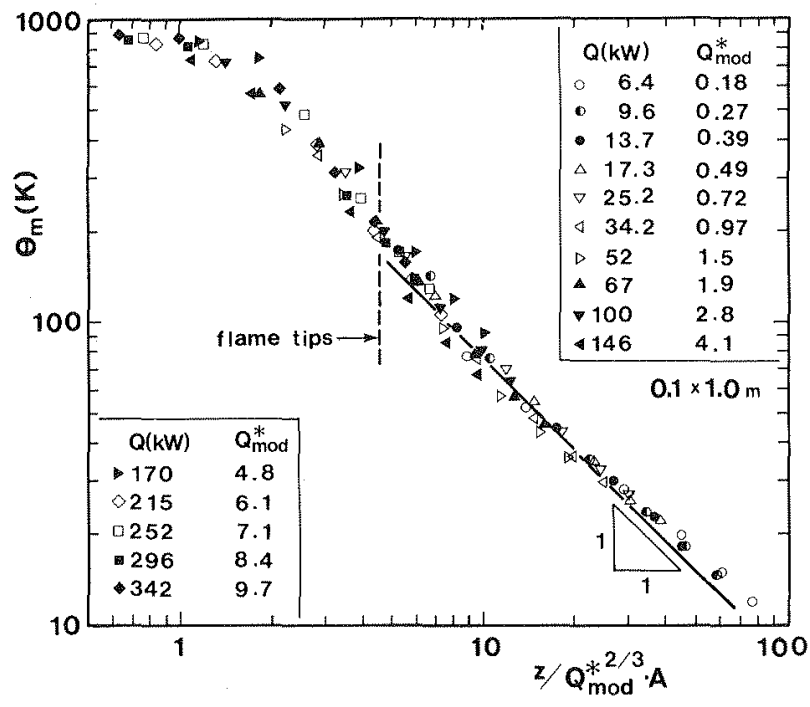
Figure 4 Maximum excess temperature vs. normalized height $\left(z / Q_{\bmod } * 2 / 3 \mathrm{~A}\right)$,
$0.10 \mathrm{~m} \times 1.0 \mathrm{~m}$ burner.

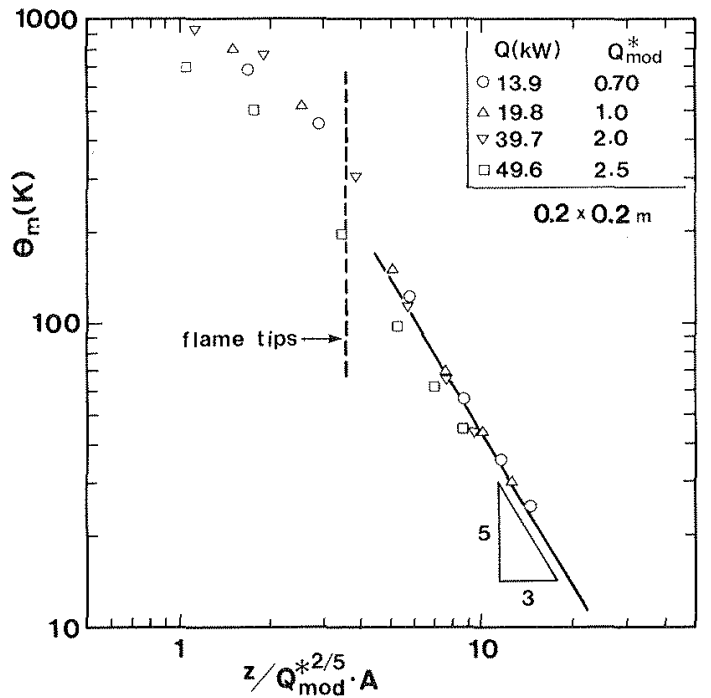

Figure 5 Maximum excess temperature vs. normalized height $\left(z / Q_{\bmod }{ }^{* 2 / 5} \mathrm{~A}\right)$, $0.20 \mathrm{~m} \times 0.20 \mathrm{~m}$ burner. 
This result implies that the line-source approximation would hold only for $\alpha \geqslant 3$, and fuels of aspect ratio $2 \sim 3$ would be transient from square to line fuels. Even though maximum excess temperature for fuels of $\alpha=2 \sim 3$ in the very far field of may also approach the point source relationship, they should be closer to a line source as far as dealing with a field in which temperature has some significance for fire safety.

\section{CONCLUSTONS}

From the results of the present experiment, the following conclusions can be drawn.

1. For heat release conditions anticipated in actual fires, there is considerable influence of fuel shape on flame height and temperature distribution in the plume above the flame.

2* Height of flame from a rectangular fuel is represented as a function of $Q^{*}$ for each aspect ratio. For a given $Q^{*}$ mod value, flame is highest for lime fuel and shortest for the square fuel. Flame height for any aspect ratio falls between these two "ideal" bounds.

3. Vertical distribution of maximum temperature at each height for $\alpha \geqslant 4$ within the region which has some significance for fire safety is almost identical to that for line fire.

4. Vertical distribution of maximum temperature for rectangular fuels of $\alpha$ $=2,3$ is close, in the flame, to the line fuel relationship and, in the plume, to the square fuel relationship.

\section{ACKNOWLEDGEMENTS}

The authors are grateful to $\mathrm{Mr}$. H. Matsumoto of Building Research Institute who designed and fabricated the burners. The authors are also indebted to Messrs. N. Nohara, Y. Shirasa, M. Naritomi, and M. Shimizu of Science University of Tokyo for their assistance in the experiments.

\section{TERMINOLOGY}

A length of the shorter side of a rectangular fuel surface, or width of line fue 1

$B$ length of the longer side of a rectangular fuel surface

$C_{p} \quad$ specific heat of air

${ }_{\mathrm{D}}^{\mathrm{P}} \quad$ characteristic fuel size

$\mathrm{L}_{\mathrm{F}} \quad$ flame height

$\mathrm{Q}^{\mathrm{F}}$ heat release rate

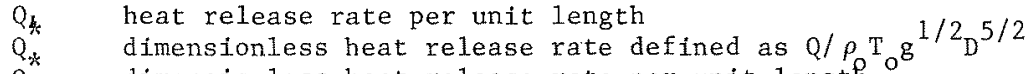

$Q_{*} \quad$ dimensionless heat release rate per unit length

$Q$ mod modified dimensionless heat release rate defined as $Q / \rho_{0} T_{0} g^{1 / 2} A^{3 / 2} B$

I mod absolute temperature

g gravitational acceleration

$\alpha$ aspect ratio $(B / A)$

$\rho$ density

$\theta$ excess temperature

suffix

o ambient 
Figure 6

Maximum excess temperatuxe/ys. normalized height $\left(z / Q_{\bmod }\right.$ $0.20 \mathrm{~m} \times 1.0 \mathrm{~m}$ burner

Figure 8

Maximum excess temperature, ys. normalized height $\left(z / Q_{\bmod }\right.$ $0.20 \mathrm{~m} \times 0.6 \mathrm{~m}$ burner

\section{Figure 10}

Maximum excess temperature $y s$. normalized height $(\mathrm{z} / \mathrm{Q} \bmod$ $0.20 \mathrm{~m} \times 0.6 \mathrm{~m}$ burner
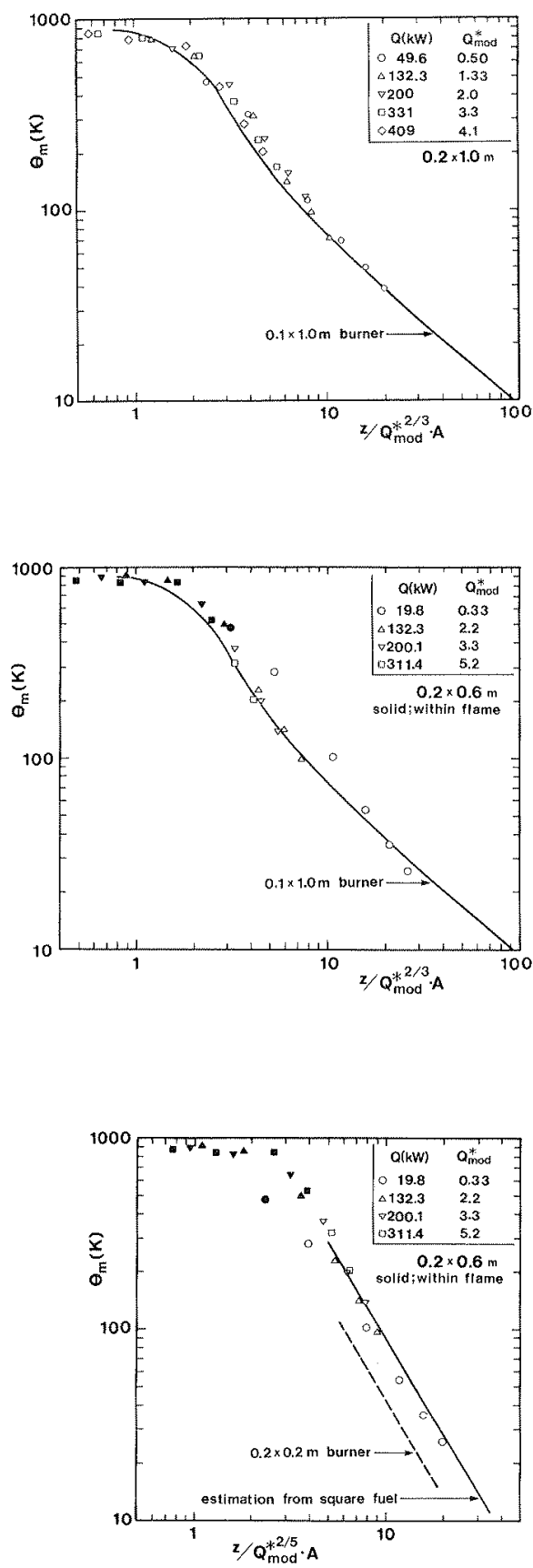
Figure 7

Maximum excess temperature $\mathrm{ys}$. normalized height $(z / 0 \bmod$ $0.20 \mathrm{~m} \times 0.8 \mathrm{~m}$ burner

Figure 9

Maximum excess temperature $\mathrm{xs}$. normalized height $\left(\mathrm{z} / \mathrm{Q}_{\bmod }\right.$ $0.20 \mathrm{~m} \times 0.4 \mathrm{~m}$ burner

\section{Figure 11}

Maximum excess temperatur ${ }_{2}$ Y5. normalized height $(\mathrm{z} / \mathrm{Q} \bmod$ $0.20 \mathrm{~m} \times 0.4 \mathrm{~m}$ burner
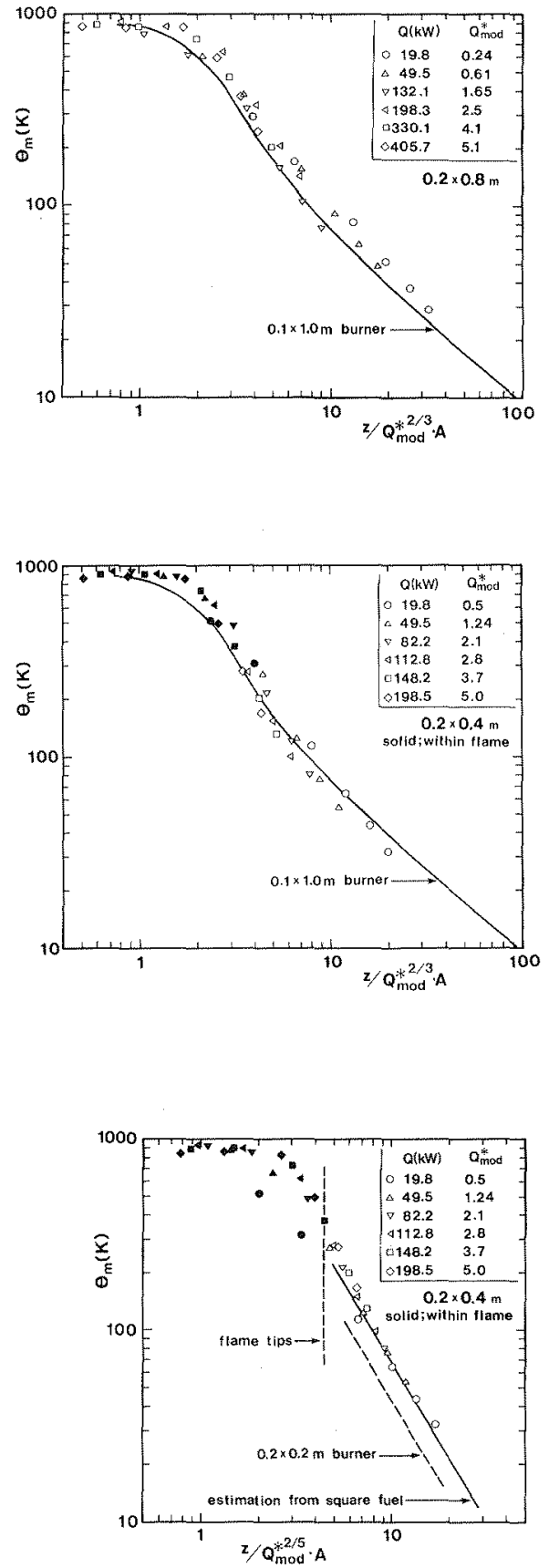


\section{REFERENCES}

1. Thomas,P.H., Webster,C.T., and Raftery,M.M.: Some experiments on buoyant diffusion flames. Combustion and Flame, Vo1.5, pp359-367, 1961.

2. Steward,F.R.: Prediction of the height of turbulent diffusion buoyant flames. Combustion Science and Technology, Vol.2, pp203-212, 1970.

3. McCaffrey,B.J.: Purely buoyant diffusion flames: some experimental results. NBSIR-79-1910, 1979 .

4. Cox,G., and Chitty,R.: A study of the deterministic properties of unbounded fire plumes. Combustion and Flame, Vol.39, pp191-209, 1980.

5. Zukoski,E.E., Kubota,T., and Cetegen,B.: Entrainment in fire plumes. Fire Safety Journa1, Vo1.3, pp107-121, 1980/81.

6. Heskestad,G.: Luminous heights of turbulent diffusion flames. Fire Safety Journa1, Vo1.5, pp103-108, 1983.

7. Hasemi,Y., and Tokunaga,T.: Some experimental aspects of turbulent diffusion flames from fire sources against a wall and in a corner of walls. Combustion Science and Technology, 1984.

8. Zukoski,E.E.: Fluid dynamic aspects of room fires. Proc. First Internationa1 Symposium on Fire Safety Science, ppl-30, 1985.

9. Hasemi,y.: Experimental wall flame heat transfer correlations for the analysis of upward wall flame spread. Fire Science and Technology, Vol.4, No.2, $\mathrm{pp} 75-90,1984$.

10. Yokot,S.: Upward current from an infinite line heat source. Bulletine of The Fire Prevention Society of Japan, Vo1.10, No.1, pp16-20, 1961.

11. Cox,G., and Chitty,R.: Some source-dependent effects of unbounded fires. Combustion and Flame, Vol.60, pp.219-232, 1985.

12. Hasemi,Y.: Deterministic properties of turbulent flames and implications for fire growth. INTERFLAM' 88 Conference Workbook, John Wiley \& Sons, pp.45-52, 1988. 